\title{
Morphometric analysis, mimicry, and color polymorphism in five species of Chauliognathus Hentz (Coleoptera, Cantharidae)
}

\author{
Vilmar Machado ${ }^{1}$ \\ Aldo M. de Araújo ${ }^{2}$ \\ Cleri S. Mosmann ${ }^{1}$
}

\begin{abstract}
This study presents data on morphometric variation for length and width of elytra in five sympatric species of the genus Chauliognathus Hentz, 1830: C. flavipes Fabricius, 1781, C. octomaculatus Pic, 1915, C. expansus Waterhouse, 1878, C. fallax Germar, 1824 and C. lineatus Zwetsch \& Machado, 2000. The meaning of this variation is discussed in the light of the theory of mimicry and visual communication between prey and predator. Females are larger than males in all species, except C. expansus. The analysis of variance for length of elytron as well as for width showed that the differences between species are significant for males and females; significant interaction (sex $x$ species) was also found. The similarity in color pattern of these species, as well as similarities in the morphometric analysis, suggests that they could form a mimetic ring of the Müllerian type, which the authors suggest be called, a "yellow-black" complex.

KEY WORDS. Coleoptera, Cantharidae, Chauliognathus, morphometry, color polymorphism
\end{abstract}

The occurrence in a given place of different species of the same genus with a similar color pattern suggests either plesiomorphism or convergence due to natural selection, constituting then an example of mimicry. This could evolve as a response to visually oriented predators or, on theoretical grounds, it could be a true convergence (if the prey is unpalatable-classic Müllerian mimicry) or the evolution toward a pattern of the protected species (Batesian mimicry). On the other hand, morphological similarity by congeneric species is better explained by commom ancestrality. In the state of Rio Grande do Sul (southern Brazil), several species of Chauliognathus Hentz, 1830 aggregate on their food sources and some of them show striking morphological similarity, including color pattern. For the species discussed here, the background elytral coloration is yellow, with or without black spots, stripes, or even a black band.

Chauliognathus is distributed in the Americas and Australia, with more than 250 species in the genus (DELKESKAMP 1939), but in spite of its wide geographical distribution studies have been made on the biology of only a few species as (e.g. MCLAIN $(1985,1986)$ on assortative mating; HowARD \& SHIELDS (1990) on enzymatic variability and MACHADO \& ARAÚJO $(1995,1998,1999)$ on color polymorphism and mating systems.

1) Laboratório de Genética, Universidade do Vale do Rio dos Sinos. Caixa Postal 275, 93022-000 São Leopoldo, Rio Grande do Sul, Brasil. E-mail: machado@bios.unisinos.br

2) Departamento de Genética, Universidade Federal do Rio Grande do Sul. Caixa Postal 15053, 91501-970 Porto Alegre, Rio Grande do Sul, Brasil.

E-mail: aldomel@portoweb.com.br 
The present work is part of a long term study of color polymorphism in Chauliognathus species as well as their morphology, cytogenetics and molecular variability. Some of the questions we are trying to answer are: 1) What mechanisms are responsible for the maintenance of color polymorphism: differential survival of morphs and/or assortative mating? 2) Do the species involved belong to a mimetic complex, and if they do, are they Müllerian mimics? 3) Can these species be discriminated on morphometric characteristics? In the present paper we try to answer the third question and to comment on its possible role in the evolution of a mimicry complex. This is accomplished by the study of about 300 individuals of both sexes belonging to five simpatric species in relation to their variability for elytral and pronotal measures.

\section{MATERIAL AND METHODS}

Specimens were collected in January 1995 from an aggregate located at the campus of the Universidade do Vale do Rio dos Sinos - UNISINOS (29 47'36"'S and $51^{\circ} 09^{\prime} 03^{\prime \prime} W$ ), São Leopoldo district, in the State of Rio Grande do Sul, Brazil. The insects were collected manually and conditioned separately in glass flasks and taken to the laboratory where measurements were performed. Whenever possible, the same number of insects of each sex were collected and, for polymorphic species the same number of insects for each morph.

The insects found in the study site belonged to five species: C. flavipes Fabricius, 1781, C. octomaculatus Pic, 1915, C. expansus Waterhouse, 1878, C. fallax Germar, 1824, C. lineatus Zwetsch \& Machado, 2000 and C. tetrapunctatus Zwetsch \& Machado, 2000. A sixth species, C. tetrapunctatus Zwetsch \& Machado, 2000 , was excluded from the present analysis due to the small number of individuals. Characterization as distinct species was based on examination of the male genitalia (ZWETSCH \& MACHADO 2000) and color pattern of the elytra and, in females, both color pattern of the elytra and of the abdomen. In species with color polymorphism for the elytra ( $C$. flavipes, $C$. octomaculatus and $C$. fallax), the individuals were distributed according to a color pattern classification system (Fig. 1).

Measurements of length and width of the elytron and of the pronotum were performed for each individual (Fig. 2), using a Mitutoyo, model CD-6 digital precision calliper. These structures were chosen because both exhibit coloration polymorphism and also because their size and color are influential in mating preferences (MCCAULEY \& WADE 1978; MCLAIN 1982). Statistical analysis was performed with NCSS software, version 6.0. Since all measures proved to be correlated (Tab. I) multivariate analysis of variance or discriminant analysis was excluded. The original values were transformed into logarithms.

\section{RESULTS}

Table II shows the means and standard deviations (in the original units) for all measures in both sexes and in the different species. A bifactorial analysis of variance (species and sex) showed that, for all variables (except for length of pronotum), significant interaction occurred between species and sex. Here only the 


\begin{tabular}{|c|c|c|c|}
\hline Species/Morphs & LIGHT & INTERMEDIATE & D A R K \\
\hline \multicolumn{4}{|l|}{ C. flavipes } \\
\hline \multicolumn{4}{|l|}{ C. fallax } \\
\hline \multicolumn{4}{|l|}{ C. octomaculatus } \\
\hline \multicolumn{4}{|l|}{ C. expansus } \\
\hline C. lineatus & & & \\
\hline
\end{tabular}

Fig. 1. Pattern of variation in elytral color for the five species of Chauliognathus dealt with in the present paper. Chauliognathus expansus males at left, females at right.

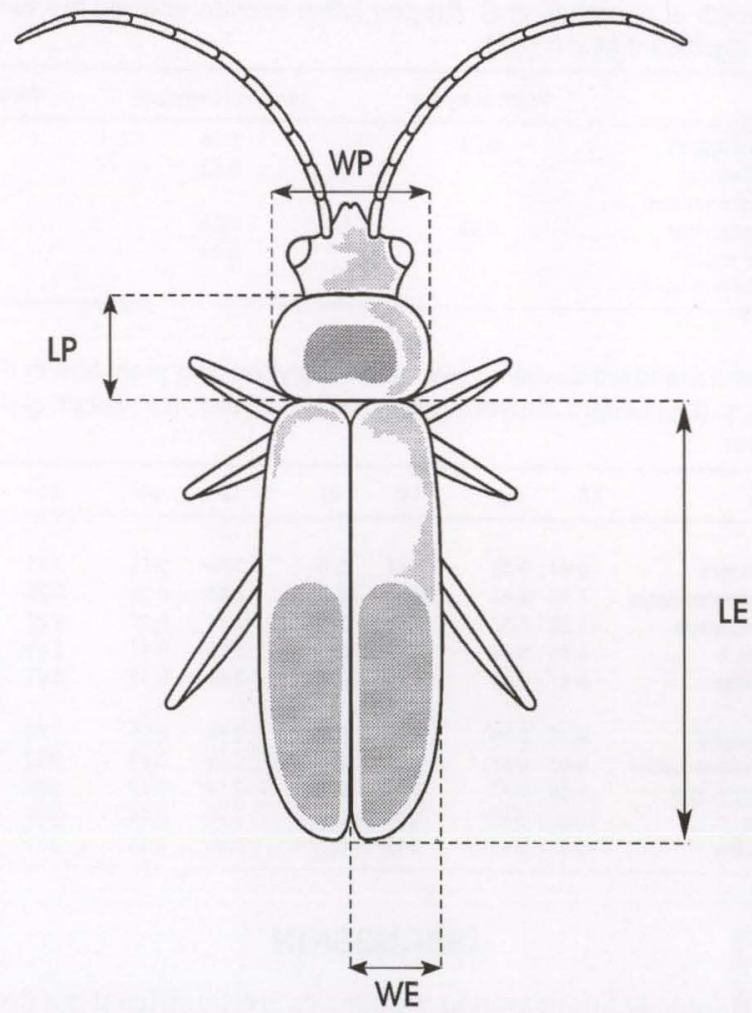

Fig. 2. Schematic representation of the measures taken on the pronotum and elytron of Chauliognathus spp. (LE) Length of elytron, (WE) width of elytron, (LP) length of pronotum, (WP) width of pronotum. 
measures of elytra are discussed, since these structures correspond to most of the phenotype exhibited by the insects to possible predators and also because they show color polymorphism.

Analysis of variance for the length of elytron showed that the differences are highly significant: males $F=143.00$ (d.f. $=4,135 ; \mathrm{p}<0.0001$ ); females $\mathrm{F}=17.03$ (d.f. $=4,135 ; p<0.001$ ). Duncan's test separated the males into four groups (Fig. 3): $C$. expansus, with the highest mean $(11.02 \mathrm{~mm})$, followed by $C$. lineatus and the pair $C$. flavipes $/ C$. fallax and C. octomaculatus, with the lowest mean $(7.70 \mathrm{~mm})$. For females, there are only three groups with $C$. expansus joining the pair $C$. flavipes/C. fallax.

Concerning the variation in width of the elytron, the results of the ANOVA was $F=306.60$ (d.f. $=4,125 ; p<0.001$ ) for males and $F=5.38$ (d.f. $=4,125 ; p<$ 0.001 ) for females. In the males only three groups were formed and in this case $C$. lineatus clustered with $\mathrm{C}$. flavipes and $C$. fallax; in the females only two groups were formed, with $C$. octomaculatus being, as before, the smallest species.

Table I. Correlation matrix for the variables length of elytron, width of elytron, length of pronotum, and width of pronotum in C. flavipes (other species showed the same results). All correlations are significant at $\propto=0.01$

\begin{tabular}{clccc}
\hline & Width of elytron & Length of pronotum & Width of pronotum \\
\hline \multirow{2}{*}{ Males } & Length of elytron & 0.70 & 0.76 & 0.62 \\
& Width of elytron & & 0.73 & 0.62 \\
& Length of pronotum & 0.83 & 0.81 & 0.62 \\
Males & Length of elytron & & 0.86 & 0.81 \\
& Width of elytron & & 0.83 \\
& Length of pronotum & & 0.88 \\
\hline
\end{tabular}

Table II. Mean and standard deviation (sd, $\mathrm{mm}$ ) for elytron and pronotum in the five species of Chauliognathus. (LE) Length of elytron, (WE) width of elytron, (LP) length of pronotum, (WP) width of pronotum.

\begin{tabular}{lrllllllll}
\hline \multicolumn{1}{c}{ Species } & LE & Sd & LE & sd & LE & sd & LE & sd & $n$ \\
\hline Males & & & & & & & & & \\
Chauliognathus lavipes & 8.84 & 0.36 & 2.77 & 0.17 & 2.46 & 0.13 & 3.61 & 0.26 & 50 \\
Chauliognathus octomaculatus & 7.70 & 0.45 & 2.38 & 0.10 & 2.23 & 0.13 & 3.20 & 0.20 & 14 \\
$\quad$ Chauliognathus expansus & 11.02 & 0.37 & 4.46 & 0.15 & 2.71 & 0.10 & 4.27 & 0.17 & 20 \\
Chauliognathus sp. 1 & 9.79 & 0.50 & 2.84 & 0.19 & 2.85 & 0.17 & 3.85 & 0.26 & 20 \\
Chauliognathus fallax & 8.81 & 0.44 & 2.74 & 0.15 & 2.45 & 0.12 & 3.61 & 0.21 & 36 \\
Females & & & & & & & & & \\
$\quad$ Chauliognathus lavipes & 9.42 & 0.49 & 3.12 & 0.21 & 2.62 & 0.16 & 8.82 & 0.25 & 44 \\
$\quad$ Chauliognathus octomaculatus & 8.92 & 0.47 & 2.91 & 0.14 & 2.56 & 0.14 & 3.72 & 0.27 & 14 \\
Chauliognathus expansus & 9.69 & 0.40 & 3.16 & 0.18 & 2.58 & 0.12 & 3.62 & 0.20 & 20 \\
$\quad$ Chauliognathus sp. 1 & 10.20 & 0.58 & 3.09 & 0.18 & 2.95 & 0.14 & 3.99 & 0.22 & 20 \\
Chauliognathus fallax & 9.52 & 0.40 & 3.12 & 0.17 & 2.61 & 0.15 & 3.79 & 0.22 & 36 \\
\hline
\end{tabular}

\section{DISCUSSION}

The differences found among the species are significant but do not allow the full separation of species based on the measurements performed, for example, $C$. flavipes and $C$. fallax were not separated in either analysis. This similarity could be important, were they mimetic species; moreover, these species present a marked 
parallel polymorphism for elytra color pattern. In C. flavipes nine morphs are found and in C. fallax six (Fig. 1). The morphs found in these two species are very similar indeed to each other, and even similar to other morphs found in the other three species. Two species are monomorphic, $C$. expansus and $C$. lineatus although easily distinguished (Fig. 1).

The differences in size between males and females is a common feature in insects. The larger size of $C$. expansus males is due to the presence of lateral expansion in their elytra, which are transparent and do not change the male color pattern. Females, on the contrary, are indistinguishable morphometrically from $C$. flavipes and C. fallax (Fig. 3 and Tab. II).

\section{Males}

LE

oct $<$ fal fla $<$ sp $1<\exp$

WE

oct $<$ fal fla $\quad$ sp1 $<$ exp

\section{Females}

LE

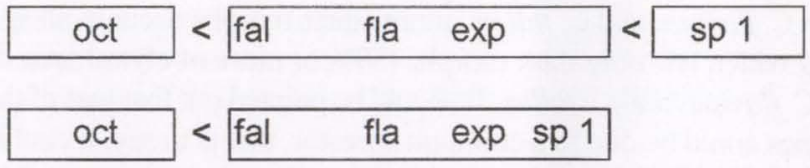

Fig. 3. Clustering of species according to the significant differences between the means of the variables; Duncans' test with $\alpha=0,01$ (see figure 2). Species: (fla) C. flavipes (exp) $C$. expansus, (oct) C. octomaculatus, (sp) Chauliognathus sp. 1, (fal) C. fallax.

The similarity in color patterns in all these species, as well as that obtained from morphometric analysis, suggests that they could form a Müllerian-type mimicry ring, which could be called a "yellow-black" complex. Although palatability tests with these beetles are not reported in the literature, an unpublished investigation by $\mathrm{J}$. VASCONCELLOS-NETO (personal communication) suggests that they are distasteful to some insectivorous birds. We also performed some palatability experiments with domestic chickens. The percentage of avoidance towards C. flavipes, C. fallax, and $C$. octomaculatus was strikingly high, being greater than $87 \%$ (FERNANDES et al. unpublished data). The presence of defensive secretions and their chemical nature were studied by MEINWALD et al. (1968) for C. lecontei Champ, 1914; MOORE \& BROWN (1978) for C. pulchellus Pic, 1930; EISNER et al. (1981) for C. pennsylvanicus De Geer, 1774 and by BRown et al. (1988) for C. lugubris Pic, 1930.

To provide protection, the similarity between species should be such as to remind the predator of an unpleasant experience with similar prey, since selection for mimicry does not necessarily affect all aspects of the morphology of an organism, but rather only those involved in signaling properties unpleasant to predators. In this context the differences in species size cannot be perceived by predators or does 
not interfere in the signaling of their unpalatability, and in this case selection for mimicry would be more marked on the color patterns. In C. pennsylvanicus, a neartic species, the frequency of color patterns is not different between sexes, with females larger than males (MASON 1976). According to him this similarity is the result of selection for Müllerian mimicry between males and females.

Experimental studies have demonstrated that even superficial similarities confer some advantage to the mimics (PILECKI \& O'DONALD 1971; EDMUNDS 1974). Furthermore, predators apparently generalize a color pattern, recognizing an organism by its general appearance (IKIN \& TURNER 1972).

The small differences observed in width and position of the spots possibly does not interfere in signaling unpleasant properties in these species. The message sent to the predators could be associated with the contrast between yellow and black. The color pattern of an organism could also be involved in intra-specific communication (TURNER 1977; ENDLER 1980, 1988), which could influence the differences in shape and position of the black spots on the elytra of these species.

Our data shows that three, or at most four, groups can be morphometricaly recognized (Fig. 3) and, interestingly, morph variability can be grouped into three categories as far as coloration is concerned: light, intermediate and dark, though these are independent of species (Fig. 1). Light morphs are those without spots or bands occurring in C. flavipes and C. fallax; intermediate morphs occur in all species except C. expansus which has only dark morphs ( $50 \%$ or more of elytral area dark) similar to those in C. flavipes and C. fallax. It should be pointed out that part of this similarity among species could be due to a common ancestor, that is to say, it could correspond to a plesiomorphism. We are not at present able to distinguish between this possibility and the possibility of mimicry, although we believe that the available data point to mimicry. The simple fact that they share common ancestry do not invalidate the possibility of evolution of mimicry in these species (a well known example is given by the pair of butterfly species, Heliconius erato and $H$. melpomene).

The stabilizing selection exerted by predators should theoretically prevent color polymorphism in Müllerian rings, but even so there are several examples of the occurrence of polymorphisms in these rings (e.g OWEN 1970; BROWN \& BENSON 1974; PAPAGEORGIS 1975). We do not currently have information which allows the identification of the set of factors enabling color polymorphism in the three species of Chauliognathus analyzed in this study. An important possible factor could be the density of aggregates formed by these species. According to BROWN \& BENSON (1974) very common unpalatable species release themselves from the normalizing selection for pattern uniformity exerted by predators. This release is a result of the fact that the number of insects consumed during the learning period of the predators would be small compared with the total number of insects in the aggregate. A more complex situation is that modeled by ENDLER (1988) in which a polymorphism can evolve if more than one species of predator is involved.Finally, the polymorphism could be maintained if some sort of assortative mating is occurring. Despite this process being stated in a previous paper on C. fallax (DIEHL-FLEIG \& ARAÚJO 1991) it was not supported in more detailed analysis (MACHADO \& ARAÚJO 1999). 
ACKNOWLEDGMENTS. Thanks are due to Conselho Nacional de Desenvolvimento Cientifico e Tecnológico (CNPq) and to Financiadora de Estudos e Projetos (FINEP) for the financial support.

\section{REFERENCES}

BRown JR., K.S. \& W. BENSON. 1974. Adaptive polymorphism associated with multiple Müllerian mimicry in Heliconius numata (Lepid. Nymph.). Biotropica 6 (4): 205-228.

Brown, W.V.; M.J. L^CEY \& B.P. MOORE. 1988. Dihydromatricariate-based triglycerides, glyceride ethers, and waxes in the Australian soldier beetle, Chauliognathus lugubris (Coleoptera: Cantharidae). Jour. Chem. Ecol. 14 (2): 411-423.

Delkeskamp, K. 1939. Coleopterorum Catalogus. Pars 165. Cantharidae. Gravenhage, Verlag für Naturwissenschaften, W. Junk Ed., 356p.

DieHL-Fleig, E. \& A.M. ARaúso. 1991. O polimorfismo cromático em uma população natural de Chauliognathus fallax (Coleoptera: Cantharidae) do Rio Grande do Sul. Rev. Brasil. Biol. 51 (3): 515-520.

EDMUNDS, M. 1974. Defense in animals. New York, Longman, 357p.

Eisner, T.; D. Hill; M. Goetz; S. Jain; D. Alsop; S. Camazine \& J. Meinwald. 1981. Antifeedant action of Z-dihidromatricaria acid from soldier beetles (Chauliognathus spp). Jour. Chem. Ecol. 7: 1148-1158.

ENDLER, J.A. 1980. Natural selection on color patterns in Poecilia reticulata. Evolution 34 (1): 76-91. 1988. Frequency-dependent predation, crypsis and aposematic coloration. Phil. Trans. R. Soc. Lond. (B319): 505-523.

HowARD, D.J. \& W.M. SHIELDS. 1990. Patterns of genetic variation within and among species of Chauliognathus (Coleoptera: Cantharidae). Ann. Entomol. Soc. Amer. 83 (3): 326-334.

IKIN, M. \& J.R.G. TURNer. 1972. Experiments on mimicry: Gestalt and evolution of genetic linkage. Nature 239: 525-527.

Machado, V. \& A.M. Araúso. 1994-1995. The colour polymorphism in Chaliognathus flavipes (Coleoptera: Cantharidae) I. Geographic and temporal variation. Evol. Biológica 8/9: 127-139. 1998. Padrões de emergência em populações naturais de duas espécies de Chauliognathus (Coleoptera, Cantharidae). Revta bras. Ent. 41 (2-4): 235-238.

-1999. Color polymorphism in Chauliognathus flavipes Fabricius (Coleoptera, Cantharidae). II. Patterns of emergence of morphs and mating systems. Revta bras. Zool. 16 (2): 441-446.

MAson, L.G. 1976. Color variation and bisexual Müellerian mimicry in an aposematic insect. Evolution 30: 841-846.

MCCAULEY, D.E. \& M.J. WADE. 1978. Female choice and mating structure of a natural population of the soldier beetle, Chauliognathus pennsylvanicus. Evolution, 32 (4): 771-775.

MCLAIN, D.K. 1982. Density dependent sexual selection and positive phenotypic assortative mating in natural population of the soldier beetle, Chauliognathus pennsylvanicus. Evolution 36 (6): 1227-1235.

MCLaIN, D.K. 1985. Clinal variation in morphology and assortative mating in the soldier beetle, Chauliognathus pennsylvanicus (Coleoptera: Cantharidae). Biol. Jour. Linn. Soc. 25: 105-117.

. 1986. Niche differentiation and the evolution of ethological isolation in a soldier beetle hybrid zone. Oikos 47: 159-167.

Meinwald, J.; Y.C. MeInWAld; A.M. Chalmers \& T. Eisner. 1968. Dihydromatricaria acid: acetylenic acid secreted by soldier beetle. Science 160: 890-892

Moore, B.P. \& W.V. Brown. 1978. Precoccineline and related alkaloids in the Australian soldier beetle, Chauliognathus pulchellus (Coleoptera: Cantharidae). Insect Biochem. 8: 393-395.

OWEN, D.F. 1970. Mimetic polymorphism and palatability spectrum. Oikos 21: 33-336.

PAPAGEORGIS, C. 1975. Mimicry in neotropical butterflies. Amer. Scient. 63: 522-32.

PILECKI, C. \& P.O'DONALD. 1971. The effects of predation on artificial mimetic polymorphisms with 
perfect and imperfect mimics at varying frequencies. Evolution 25: 365-370.

TURNER, J.R.G. 1977. Butterfly mimicry: The genetical evolution of an adaptation. Evol. Biol. 10: 163-203.

ZWETSCH, A. \& V. MACHADO. 2000. Estudo morfológico do edeago das espécies de Chauliognathus

Hentz, 1830 (Coleoptera: Cantharidae) do complexo "amarelo-preto". Acta Biol. Leopoldensia, São Leopoldo, 22 (2): 193-203.

Recebido em 29.VI.2000; aceito em 16.VII.2001. 